\title{
PENSANDO AS MASCULINIDADES CONTEMPORÂNEAS
}

\author{
THINKING ABOUT CONTEMPORARY MALE
}

\begin{abstract}
BAYDOUN, Mahmoud. Não sou nem curto afeminados: Reflexões viadas sobre a efeminofobia nos Apps de pegação. Salvador: Editoria Devires, 2020.
\end{abstract}

Nas últimas décadas, observa-se um crescimento significativo nas produções nacionais acerca das masculinidades (CALDAS, 1997; ARILHA, UNBEHAUM \& MEDRADO, 1998; SCHPUN, 2004; NETO, 2017; CAETANO \& SILVA JUNIOR, 2018; THÜRLER \& MEDRADO, 2020). A partir de diferentes campos disciplinares, com perspectivas teóricas e metodológicas distintas, autores e autoras têm se debruçado a refletir e problematizar as nuances e complexidades que cercam "o mundo dos homens". É no bojo dessa expansão reflexiva que podemos compreender a publicação do livro "Não sou nem curto afeminados: Reflexões viadas sobre a efeminofobia nos Apps de pegação" de autoria do psicólogo e sexólogo Mahmoud Baydoun.

Resultado de sua dissertação de mestrado defendida no Programa de PósGraduação em Psicologia da Universidade Federal de Rondônia (UNIR) em 2017 (intitulada “Não sou nem curto afeminados': reflexões viadas sobre a masculinidade hegemônica e a efeminofobia no Grindr"), "Não sou nem curto Afeminados" traz uma importante contribuição para o campo de estudos sobre masculinidades contemporâneas ao problematizar os modos pelos quais se produz e reiteram os ideais de masculinidade hegemônica no interior dos aplicativos de pegação.

A obra, dividida em oito capítulos e em estreito diálogo com a teoria Queer, cuja leitura crítica e situada é "torcida" e (re)interpretada a partir do que o autor chama de "estudos viados", descortina os perversos mecanismos das efeminofobias no interior das relações homodesejantes na cidade de Porto Velho (RO). Ao longo do capítulo 1, "Por que este livro"?, a partir de memórias de sua própria trajetória pessoal, o autor apresenta as motivações que o estimularam no desenvolvimento da pesquisa. No capítulo 2, "A efeminofobia nas relações homodesejantes", o aplicativo Grindr é apresentado como uma "faca de dois gumes", ou seja, possibilidade de prazer e ao mesmo tempo produtor de homofobia/preconceito. O capítulo 3, "Um breve histórico das relações homodesejantes mediadas on-line”, é dividido em três partes: na primeira, apresenta-se um breve panorama das conquistas referentes aos direitos civis e sexuais da população LGBT; na segunda, o modo de funcionamento do Grindr; e na terceira, algumas das principais pesquisas já realizadas sobre o uso do aplicativo.

Esmael Alves de Oliveira

Doutor em Antropologia Social (PPGAS/UFSC). Docente do Programa de Pós-Graduação em Antropologia (PPGAnt) e do Programa de Pós-Graduação em Psicologia (PPGPsi) da Universidade Federal de Grande Dourados (UFGD). E-mail: esmaeloliveira@ufgd.edu.br 
No capítulo 4, "Contribuições dos estudos viados", tomando como referência a importância da teoria Queer, Baydoun realiza uma genealogia dos "estudos viados". No capítulo 5, "Masculinidade hegemônica e efeminofobia", são descortinadas didaticamente categorias chaves nos estudos de gênero e sexualidades e que, de acordo com o autor, ajudam a compreender a efeminofobia e os ideais hegemônicos de masculinidade, tais como: sexo, gênero, identidade de gênero, expressão de gênero e orientação afetivo-sexual. Em "Como aconteceu à pesquisa?” (capítulo 6), são apresentados os aspectos metodológicos da pesquisa. Em 'Pareça heterossexual', mesmo que não seja: discussões e reflexões viadas” (capítulo 7), tomando como base tanto descrições colhidas na plataforma do Grindr, quanto entrevistas realizadas com alguns usuários, são apresentadas as diferentes formas pelas quais se produz a abjeção do efeminamento e a imposição dos ideais de masculinidade. Por fim, no capítulo 8, "Considerações finais", o autor retoma alguns pressupostos desenvolvidos ao longo dos capítulos anteriores para concluir que as relações no interior do Grindr possuem um "ethos que replica as hierarquias e relações de poder historicamente perpetuadas" (p. 139).

Mas o que seria essa efeminofobia e quais seus efeitos na masculinidade idealizada pelos usuários da plataforma Grindr? Definida pelo autor como "preconceito que vitima meninos/homens efeminados ou que não se enquadram no padrão hegemônico de masculinidade" (p. 22), a efeminofobia possui uma dimensão englobante à medida que atravessa tanto vítimas quanto perpetradores e se manifesta rotineiramente nos aplicativos de pegação por meio da expressão "ser discreto".

Com o objetivo de "compreender como a busca de parceiros para relações homodesejantes mediadas digitalmente reflete os padrões socioculturais e históricos que têm como paradigma a heterossexualidade, na figura do homem másculo" (p. 77), Baydoun realizou um trabalho de campo tanto no contexto on-line (utilizando o aplicativo Grindr) quanto off-line. Em termos metodológicos, cruzando referenciais da psicologia e das ciências sociais à luz da teoria Queer (nomeada pelo pesquisador de "estudos viados" ou "teoria viada"), o trabalho utilizou-se amplamente da etnografia virtual por meio da pesquisa on-line e off-line. Na etapa off-line foram entrevistados dez usuários do aplicativo nas faixas etárias de 19 a 37 anos.

A partir dos dados de campo encontrados, o autor descortina os elementos que sustentam o dispositivo “parecer heterossexual”. É assim que no capítulo sete, que pela densidade dos dados apresentados e pela análise empreendida pode ser considerado o cerne da obra, é apresentado tanto os aspectos sutis quanto os evidentes do ideal hegemônico de masculinidade que cercam e constituem os discursos efeminofóbicos de um "ser discreto". Em cena, discursos/noções/critérios de objetividade (dispenso afeminados), de isenção (nada contra), discrição e sigilo (nada de mimimi), aparência hétero (não ter trejeitos), dentre outros, e que, segundo o autor, são reveladores de que "por trás dessa miríade de 'não curto afeminados' dentro do aplicativo, estão toda a abjeção, a rejeição e a subalternização infligidas social e historicamente ao homem efeminado" (p. 92). 
Para além da dimensão mais evidente do preconceito e que se manifesta justamente na desqualificação de sujeitos afeminados e/ou que destoam das normas hegemônicas da inteligibilidade cisheteronormativa, os dados encontrados por Baydoun também evidenciam a existência de perversos mecanismos de exclusão sustentados nos marcadores sociais de diferença. Não por acaso, afirma o autor: "A propagação dos ideais de masculinidade hegemônica entre homens que buscam relações homodesejantes, entretanto, não se pauta apenas na supremacia do 'macho, discreto e fora do meio' sobre os outros tipos de porte físico, mas também na reiteração de hierarquias e lógicas binárias que englobam outros aspectos da identidade, como papel sexual [ativos], a classe social [pertencentes a camadas abastadas e/ou possuidores de bens simbólicos socialmente valorizados], a idade [abaixo dos 30 anos] e a racialização [preferencialmente brancos, onde homens negros são "bem vindos" apenas na condição de ativos e bem dotados]" (p. 120 - acréscimo nosso).

Por fim, ao (d)enunciar a existência de um "shopping da carne” (p. 130), o autor expõe contundentemente a complexidade imposta pelas díades "consumidoresprodutos", "corpos-produtos" em que ser "macho, discreto, fora do meio, sarado, ativo, rico, jovem, branco e que 'parece heterossexual”' (p. 135) é o preço imposto pela masculinidade hegemônica para se acessar e ser escolhido o/no mercado do desejo. Nesse mercado seletivo, "dificilmente são vendáveis os consumidores-produtos considerados efeminados, magros/gordos, 'só passivos', pobres, mais velhos, nãobrancos e que não conseguem 'passar por heterossexuais' e que são repelidos para o campo do abjeto" (p. 136).

É importante destacar que a obra em tela é rica de questões e de maneira alguma se esgotam nos aspectos aqui destacados. Para fins de análise e de diálogo destacarei alguns pontos.

Primeiro, não há dúvida quanto a importância da obra para o campo de estudos sobre masculinidades. Trata-se de um trabalho consistente em termos teóricos e que traz importantes insights não apenas para a compreensão das masculinidades contemporâneas, mas também sobre os processos de subjetivação presentes nos processos de interação mediados pelas plataformas digitais.

Segundo, a pesquisa não apenas endossa o que já havia sido constatado em pesquisas anteriores realizadas no Brasil sobre sexualidades e plataformas digitais (inclusive bem referenciadas ao longo do livro - MISKOLCI, 2009, 2013), mas vai além ao privilegiar uma análise que reconhece tanto a importância dos marcadores sociais de diferença no campo das masculinidades como também a dimensão englobante da inteligibilidade cisheteronormativa. Em relação a este último aspecto nos chama a atenção o cuidado analítico empreendido pelo autor no reconhecimento de que "mesmo homens que não se enquadravam no padrão hegemônico de masculinidade e já haviam saído do armário reproduziam esse tipo de discurso” (p. 17).

Como terceiro e último aspecto é importante destacar que o trabalho de Mahmoud Baydoun faz eco a outros trabalhos que apontam a existência de uma série de normatividades no interior do segmento LGBT e que são produtores de desigualdades (FRANÇA, 2006; HENNING, 2008). Isso nos possibilita pensar que 
a luta por reconhecimento e visibilidade quando não ancorada numa perspectiva interseccional e no reconhecimento de privilégios, tende a manter intocáveis e naturalizadas as relações hierarquizadas e produtoras de subalternidades. Se isso é válido para o campo dos estudos de gênero e sexualidade, o mesmo pode ser dito em relação ao campo das masculinidades. Afinal, qual o lugar que tem ocupado (inclusive na produção acadêmica mainstream) as masculinidades não hegemônicas - cite-se negra, indígena, pobre, favelada, não cristã, idosa?

Apesar dessas qualidades, é preciso reconhecer na obra a presença de alguns impasses analíticos que se revelam em alguns momentos da obra e que na conclusão (capítulo 8) se tornam mais emblemáticos. Para fins de análise destaca-se alguns trechos: "são negadas aos homens outras formas de performance e expressão de gênero" (p. 138), "quem não se enquadra nos padrões impostos pela matriz heterossexual é lançado para fora do 'mercado' virtual de homo-desejos” (p. 138), “os desejos vão se constituindo imperceptivelmente como excludentes e segregatícios"

Acreditamos que ao se debruçar sobre a internalização dos discursos machofacistas e efeminofóbicos, preocupado com a dimensão hierárquica, Baydoun acabou por incorrer no equívoco de considerar poder como uma relação unilateral. Assim entendido, poder seria algo que alguns têm e outros não. Isso não seria um problema (há inclusive perspectivas teóricas alinhadas a esse entendimento) não fosse a perspectiva "viada" (Queer) à qual o autor afirma estar atrelado. Se, conforme nos aponta Foucault, "não há relações de poder sem resistência" (2006, p. 49), há que se considerar qual a margem de manobra também presente mesmo em contextos marcados pela matriz de inteligibilidade cisheteronormativa. Uma análise que desconsidere isso, o risco é de endossar que os dispositivos disciplinares têm a última palavra e que não há outra possibilidade além da captura dos sujeitos e das subjetividades. Ao contrário, o poder "não é uma instituição nem uma estrutura, não é uma certa potência de que alguns sejam dotados: é o nome dado a uma certa situação estratégica complexa numa sociedade determinada" (FOUCAULT, 1988, p. 89).

Em relação a isso, como desconsiderar, por exemplo, que mesmo diante de requisitos tão normativos e não correspondendo ao "shopping da carne", há aqueles que deliberadamente não deixam de acessar tais plataformas? Ou mesmo aqueles que encontram/criam estratégias bastante perspicazes e criativas para driblarem as normatividades hegemônicas? É como se Baydoun, no desejo de encontrar nos dados de campo os sistemas de opressão para confirmar suas hipóteses, deixasse escapar o que "gritam" seus próprios dados de campo. Ao longo da leitura da obra é impossível não perceber a existência de margens de manobra e de agenciamento nas performances empreendidas por figuras como Caio e Abelardo. Em relação ao primeiro, diante do dispositivo inquisidor de "discrição", a tática do "puxar assunto" (p. 95). Em relação ao segundo, face à demanda por ser "macho", o criar um nick "fake" já que é "esse fake que as pessoas desejavam" (p. 117). Portanto, apesar disso, parece que Baydoun em sua sede de (d)enunciar os efeitos deletérios (e de fato eles existem!), perdeu a potente oportunidade de privilegiar os pontos de fuga, as elipses, 
as incoerências, os entre-lugares (e eles também existem!). Em seu anseio de pensar o desejo como negação, escapou a possibilidade de pensar o desejo também como produção (DÍAS-BENÍTEZ, 2017; FERREIRA, 2008).

À guisa de conclusão, em tempos tão marcados pelos discursos autoritários, pela violência sexista e lgbtfóbica (que mata!), pelo racismo e xenofobia, as reflexões de Mahmoud Baydoun soam como um convite para que não ignoremos as contradições e ambiguidades que enredam e constituem as masculinidades hegemônicas contemporâneas. O grande convite-desafio é que continuemos a problematizar, desnaturalizar e questionar os modelos de masculinidade(s) produtores dessas e de outras mazelas sem perdermos de vista que hegemonia rima sempre com contrahegemonia.

\section{Referências}

ARILHA, Margareth; UNBEHAUM, Sandra G. \& MEDRADO, Benedito. Homens e masculinidades: outras palavras. São Paulo: ECOS/Ed. 34, 1998.

CAETANO, Marcio \& SILVA JUNIOR, Paulo Melgaço da. De guri a cabra-macho: masculinidades no Brasil. Rio de Janeiro: Lamparina, 2018.

CALDAS, Dario (Org.). Homens: Comportamento, sexualidade, mudança. São Paulo: Editora SENAC, 1997.

DÍAS-BENÍTEZ, María Elvira. Uma etnografia das derivas do desejo. In: BARRETO, Victor Hugo de Souza. Vamos fazer uma sacanagem gostosa? Uma etnografia da prostituição masculina carioca. Niterói: Eduff, 2017. p. 13-20.

FERREIRA, Paulo Rogers. Os afectos mal-ditos: o indizível nas sociedades camponesas. São Paulo: Aderaldo \& Rothschild/Anpocs, 2008.

FOUCAULT, Michel. Estratégia saber e poder. Coleção: Ditos \& Escritos v. VI. Rio de Janeiro: Forense Universitária, 2006.

FOUCAULT, Michel. História da Sexualidade 1: a vontade de saber. Rio de Janeiro: Edições Graal, 1988.

FRANÇA, Isabela Lins. Cercas e Pontes: O movimento GLBT e o mercado GLS na cidade de São Paulo. Dissertação de Mestrado do Programa de Pós-Graduação em Antropologia Social da Universidade de São Paulo. São Paulo: USP, 2006.

HENNING, Carlos Eduardo. As diferenças na diferença: hierarquia e interseções de geração, gênero, classe, raça e corporalidade em bares e boates GLS de Florianópolis/ 
SC. Dissertação de Mestrado apresentada ao Departamento de Antropologia Social do Centro de Filosofia e Ciências Humanas da Universidade Federal de Santa Catarina. Florianópolis: UFSC, 2008.

MISKOLCI, Richard. O Armário Ampliado - Notas sobre sociabilidade homoerótica na era da internet. Revista Gênero, Niterói, v.9, n. 2, p. 171-190, 2009.

MISKOLCI, Richard. Machos e Brothers: uma etnografia sobre o armário em relações homoeróticas masculinas criadas on-line. Rev. Estud. Fem., Florianópolis, v. 21, n. 1, p. 301-324, 2013.

NETO, Jose Mariano (Org.). Dossiê "Crise de paradigmas tradicionais: masculinidades oscilantes, novos conceitos e desejo de mudança”. Revista Ártemis, UFPB, v. 23 n. 1, 2017 .

SCHPUN, Mônica Raisa (Org.). Masculinidades. São Paulo: Boitempo; Santa Cruz do Sul: EDUNISC, 2004.

THÜRLER, Djalma \& MEDRADO, Benedito (Orgs.). Dossiê "Masculinidades contemporâneas em disputa", Periódicus, UFBA, v. 1, n. 13, 2020.

Recebido em 25/11/2020.

Aceito em 24/05/2021. 